\title{
Higher Order Cognition and Communication: A Preliminary Study for the Development of Brief Test of Cognitive-Communication Disorders
}

\author{
Mi Sook Lee', Bo Seon Kim² \\ 'Department of Audiology and Speech-Language Pathology, Hallym University of Graduate Studies, \\ HUGS Center for Hearing and Speech Research, Seoul, Korea \\ ${ }^{2}$ Seoul Asan Rehabilitation Clinic, Incheon, Korea
}

Received: April 23, 2020

Revised: June 9, 2020

Accepted: June 30, 2020

Correspondence:

Bo Seon Kim, PhD

Seoul Asan Rehabilitation Clinic,

818 Hogupo-ro, Namdong-gu,

Incheon 21534, Korea

Tel: +82-32-466-7582

Fax: +82-32-466-7581

E-mail: bskimslp@gmail.com

\begin{abstract}
Purpose: Higher order cognition (HOC) is commonly impaired in neurological disease including mild cognitive impairment (MCI) and dementia of Alzheimer's type (DAT). The impact of this deficit is particularly prominent in communication. The purpose of this preliminary study was to investigate the correlation between $\mathrm{HOC}$ and communication in $\mathrm{MCl}$ and DAT using Brief test of CognitiveCommunication Disorders (BCCD), and to demonstrate subdomains of communication as predictors of HOC. Methods: Healthy controls $(n=40)$, persons with $\mathrm{MCl}(n=31)$ and DAT $(n=40)$ completed the subtests of HOC and communication in BCCD. HOC and communication tests consisted of 9 (organization/reasoning/problem solving/executive function) and 12 (comprehension/expression/reading \& writing/pragmatic language) items respectively. Results: The main findings were as follows. Firstly, there was a significant difference among three groups in most subdomains and total scores of HOC and communication. Secondly, HOC was significantly associated with comprehension and total score in $\mathrm{MCl}$. A significant relationship between $\mathrm{HOC}$ and all domains of communication was also observed in DAT. Thirdly, expression, pragmatic language, and total score were predictors of $\mathrm{HOC}$ in $\mathrm{MCl}$, while only total score of communication predicted $\mathrm{HOC}$ for individuals with DAT. Conclusion: This study is expected to present clinically available data in assessment and intervention for cognitive-communication disorders. Specific communication measures as powerful indicators of $\mathrm{HOC}$ may contribute to increase the diagnostic and prognostic accuracy in $\mathrm{MCl}$ and DAT.
\end{abstract}

Key Words: Communication, Correlation, Dementia of Alzheimer's type, Higher order cognition, Mild cognitive impairment.

\section{INTRODUCTION}

고차원적 인지(higher order cognition, $\mathrm{HOC}$ )는 추론, 문제 해결, 비판적 사고, 새로운 분야의 학습, 창의성 등을 발휘하는 데 필요한 과정을 이해하고 적용하는 능력으로 다면적이고 복 합적인 인지 영역에 해당한다(American Association for Advancement of Science, 2009). 즉, 기본적인 사실이나 지식을 기억하고 이해하는 데 국한되지 않고 문제를 해결하기 위해 개 념을 적용하는 능력과 관련된다. 이는 과학적 과정, 양적 추론, 모형화 및 시뮬레이션의 활용까지 확대된다(American Association for Advancement of Science, 2009).

(c) This is an Open Access article distributed under the terms of the Creative Commons Attribution Non-Commercial License (https://creativecommons.org/licenses/by-nc/4.0) which permits unrestricted non-commercial use, distribution, and reproduction in any medium, provided the original work is properly cited.
$\mathrm{HOC}$ 는 다양한 인지-의사소통 과제와 일상생활 기능에서 광범위하게 요구되는데, 구체적인 범주는 다음과 같다(Lemons \& Lemons, 2013). 1) 새로운 상황에서 정보, 방법, 개념, 이 론을 활용한다. 2) 결과를 예측하고 문제 해결을 위한 접근법 을 선택한다. 3) 하나의 문제를 개별 요소들로 분리하고 주요 요소의 양식과 구성을 이해한다(예: 분류 및 정렬). 4) 다양한 정보의 질과 중요성, 결과에 대한 가능성을 판단하고 각각에 상대적인 가치를 부여한다. 5) 추론에 근거해 선택하고 범주의 적용 및 분석, 평가를 수행한다.

$\mathrm{HOC}$ 와 지각, 실행, 언어 등이 결합하여 고차원적 정신기능 이 발휘되므로(Kumar et al., 2015), 이들은 한 개인의 직업 및 일상생활뿐 아니라 삶의 질을 좌우하는 핵심 기능 중 하나이 다. 기억력과 집행기능, 이름 대기 능력은 50세 이전부터 저하되 기 시작해 65 세 이후에는 보다 심화되는데, 신경병리학적으로는 
전두엽 및 전전두엽, 인근 연합 영역이 중년기부터 서서히 변화해 뇌 기능의 효율이 떨어지기 때문이다(Sperling et al., 2011). 이 같 은 변화는 인지 처리 속도를 늦추면서 궁극적으로 $\mathrm{HOC}$ 와 의사 소통 기능에 부정적으로 작용한다(Singh-Manoux et al., 2012).

따라서 $\mathrm{HOC}$ 와 의사소통은 상호 간에 큰 영향을 미친다. 질 문에 대답하기, 문장-그림 짝 맞추기 등 정보를 회상하거나 활 용하는 과제는 기억 속에 보유하고 있는 정보를 처리함으로써 수행할 수 있는데, 이 과정에서 $\mathrm{HOC}$ 나 작업기억과 같은 다영 역적 인지가 음운 인식, 구어 회상의 정확도, 계산 및 언어 이해 를 돕는다(Peach \& Shapiro, 2020). 실제로 알츠하이머형 치매 (dementia of Alzheimer's type, DAT)의 HOC는 읽기 및 듣기 이해력, 계산 능력과 상관성이 크다고 보고된다(Hitch et al., 2001). 또한 노화나 경도인지장애(mild cognitive impairment, $\mathrm{MCI}$ )의 영향으로 $\mathrm{HOC}$ 가 저하되면 언어 처리에 직접적인 영 향을 미친다(Borella et al., 2008). 여기에는 HOC와 연계된 다 른 인지 능력도 변수로 작용한다. 예를 들어 노인과 DAT 환자 는 억제성 기제가 약화되면서 주의력이 뚜렷이 저하된다. 즉 무 관한 사고, 개인적 관심사, 특이한 연상 작용으로 인해 언어 이 해와 회상 능력이 떨어진다. 또한 하나의 과제에서 다른 과제로 빠르게 전환하기가 어려워 도식화된 해석에 그친다(Peach \& Shapiro, 2020).

의사소통의 하위 영역 중 이해 측면에 미치는 $\mathrm{HOC}$ 의 영향 은 광범위하다. 언어 이해력의 저하는 목표에서 벗어난 장황한 발화를 유발한다. 주제와 무관하고 지나치게 많은 양의 발화는 모호하거나 제한적인 성격을 띠므로 의사소통의 효율성을 낮 추고 상호작용의 질을 경감시킨다(Pushkar et al., 2000). 따라 서 $\mathrm{HOC}$ 는 언어 이해뿐 아니라 표현 능력에도 관여한다. 예를 들 어 DAT 환자는 $\mathrm{HOC}$ 가 저하되면서 음운적 및 의미적 단어유창 성이나 대면이름대기에 어려움을 겪는다(Lee \& Kim, 2019a; Peach \& Shapiro, 2020). 또한 문법적 복잡성과 내용의 적절성 이 전제된 자발화를 산출하지 못한다(McDowd et al., 2011). 노인과 DAT의 자발화를 비교한 연구에서, 70대 중반의 노인은 구문적 복잡성과 명제의 내용 점수가 가장 낮고 DAT 환자는 연 령과 상관없이 지속적인 감퇴를 보였다(Kemper et al., 2001).

의사소통의 산출 측면도 $\mathrm{HOC}$ 가 크게 관여한다. 특히 단어 정의하기 과제는 $\mathrm{HOC}$ 를 포함한 인지-언어 영역에 민감하다. 즉 문장 수준의 의미론적인 표현에 그치지 않고 단어의 의미 처리, 사물에 대한 의미지식, $\mathrm{HOC}$ 등을 복합적으로 요구한다 (Hough, 2007). 단어 정의는 HOC와 상위 언어적(metalinguistic) 능력, 의미론적 지식을 동시에 요하기 때문에 신경학적 변 화로 인한 복합적인 인지-언어 양상을 파악하는 데 유용하다.

$\mathrm{HOC}$ 는 읽기나 쓰기와 같은 의사소통 영역에도 다양하게 작 용한다. 읽기와 쓰기는 활용되는 과제의 유형이나 방식에 따라
요구되는 기능과 영향이 다를 수 있다. 예를 들어 소리 내어 읽 기는 치매 환자의 공격성, 우울감, 행복감, 운동 능력 등 정서. 행동 측면이 관여된다(Billington et al., 2013). 또한 집행기능 의 탈억제(disinhibition), 환기(alert), 삶의 질, 회상, 발화의 정보 전달성, 어휘 산출 등이 작용하며(Billington et al., 2013; Kim $\&$ Lee, 2019a), 사회적 접촉, 자아상의 회복과 같은 심리사회적 영향도 있다(Longden et al., 2016).

쓰기 과제는 개념화나 의미 체계와 관련된다. 의미 체계의 개 념 특이적 정보가 소실된 치매 환자는 쓰기를 제대로 수행할 수 없다(Hillis et al., 2004). 경도 및 중등도의 DAT 환자를 대 상으로 한 Kim \& Lee(2019a)의 연구에 따르면 주제와 관련된 어휘 떠올리기, 핵심 어휘의 사전적 정의 읽기, 그림 자극을 보 고 핵심 어휘 쓰기, 주제와 관련된 단락 읽기, 문장 완성하기 등 $\mathrm{HOC}$ 와 언어 처리가 복합적으로 요구되는 단계적 중재는 어휘 산출을 향상시킨다.

화용언어는 $\mathrm{HOC}$ 의 영향이 가장 큰 의사소통 영역 중 하나 이다. 은유, 속담, 관용구 등의 비유언어는 문자 그대로의 해석 이 아닌 화용적 추론에 기반하여 해석한다. 이는 논리적 추론 과 달리 언어의 의미를 맥락적으로 이해함으로써 드러나지 않 은 화자의 의도를 파악하는 능력이 필요하다 $(\mathrm{McDermott} \&$ Chan, 2006). 노화나 신경병리학적 질환으로 $\mathrm{HOC}$ 가 저하되면 의미의 부호화를 반복하기 때문에 비유언어를 처리할 때 억제 기능을 제대로 발휘하지 못한다(McDermott \& Chan, 2006). 이로 인해 과제 간의 전환이 느리고, 이전에 학습된 관념이나 경험적 지식에 크게 의존한다. 또한 정보를 유지하거나 규칙의 변화를 따르지 못하며, 대안적 방법을 실행하는 능력이 떨어져 화용적 추론에 어려움을 겪는다(Lee \& Kim, 2018).

이 같은 화용적 추론은 담화 측면에도 적용된다. 즉 담화 산 출에는 $\mathrm{HOC}$ 와 언어의 의미 및 구문, 화용 측면이 통합적으로 관여되므로 노화나 신경병리학적 질환의 인지-언어 수행력을 민감하게 반영한다(Lee \& Kim, 2020). 담화를 산출하는 데 필 요한 음운 지식, 의미적 효율성, 통사적 활용, 거시 구조의 정교 화, 응집성 및 통일성, 정보 전달의 적절성 등은 $\mathrm{HOC}$ 기제에 기반한다(Hudon et al., 2006). HOC의 손상으로 인지-언어 처 리의 효율성이 저하되면 명제화된 정보를 담화 내에 조직하기 가 어렵고, 주어진 주제와 상관성이 적은 담화를 산출한다 (Kemper \& Summer, 2001).

$\mathrm{MCI}$ 나 DAT와 같은 신경병리학적 질환에서 $\mathrm{HOC}$ 와 의사소 통은 가장 두드러지게 손상되는 영역에 해당한다(Kumar et al., 2015). DAT의 경우 초기부터 HOC의 손상이 보편적으로 나타 난다(Belleville et al., 2017). HOC의 하위 영역별로 손상되는 정도가 다르지만, $\mathrm{HOC}$ 자체가 직업적 상황, 사회적 기술, 일상 생활의 다양한 과제와 요구를 수행하는 데 관여하므로 그 영향 
력은 매우 광범위하다. 특히 치매 증후군이 진행됨에 따라 $\mathrm{HOC}$ 와 언어, 지각 능력의 손상이 뚜렷해지므로(Kumar et al., 2015), HOC는 MCI에서 DAT로의 진행을 예측하는 주요 지표 로서 활용된다(Belleville et al., 2017). 또한 HOC와 의사소통 능력 간의 상관성에 기반해 $\mathrm{MCI}$ 나 DAT의 평가 및 중재 시 효 율성을 높일 수 있다. 그러므로 두 신경학적 질환군에서 $\mathrm{HOC}$ 와 의사소통의 양상이 어떻게 다르며, 양자 간에 상관성을 갖 는 하위 영역과 예측변인이 무엇인지를 규명하는 것은 임상적 으로 매우 유용할 것이다.

본 연구에서는 $\mathrm{MCI}$ 와 DAT 환자의 $\mathrm{HOC}$ 와 의사소통 능력 을 알아보고 양자 간의 상관성을 분석하고자 한다. 또 $\mathrm{HOC}$ 를 민감하게 반영하는 의사소통의 하위 영역이 무엇인지를 제시할 것이다. 이를 위해 현재 개발 중인 인지-의사소통장애 간편검 사(Brief test of Cognitive-Communication Disorders, BCCD) (Lee \& Kim, 2019b)를 활용하고자 한다. 구체적인 연구 문제 는 다음과 같다.

첫째, $\mathrm{MCI}, \mathrm{DAT}$, 통제 집단 간에 $\mathrm{HOC}$ 및 의사소통의 수행 력을 비교한다.

둘째, $\mathrm{MCI}, \mathrm{DAT}$, 통제 집단에서 각각 $\mathrm{HOC}$ 와 의사소통의 하위 능력 간에 상관성을 분석한다.

셋째, $\mathrm{MCI}, \mathrm{DAT}$, 통제 집단의 $\mathrm{HOC}$ 능력을 예측하는 의사 소통 변인을 제시한다.

\section{MATERIALS AND METHODS}

\section{연구 대상}

본 연구의 환자군은 $\mathrm{MCI} 31$ 명, 경도 중등도의 DAT 40명으 로 구성되었다. 정상 통제군에는 이들과 연령, 성별, 교육 연수 의 분포를 일치시킨 노인 40 명이 포함되었다. 이들은 수도권과 전라도, 충청도 소재의 대학병원 신경과, 데이케어센터, 대학 부 설 언어재활센터, 노인복지관, 노인정으로부터 표집되었다.

환자군의 선정 기준으로는 1) 신경과 전문의에 의해 $\mathrm{MCI}$ 와 DAT로 진단받고, 2) 임상치매척도(clinical dementia rating) (Morris, 1993)에 따라 0.5, 1, 2로 분류되며, 3) 최소 1년 이상 의 교육을 받은 자들이었다. 정상군의 선정 기준은 다음과 같
다. 1) 한국형 간이정신상태검사(Korean mini-mental state examination, K-MMSE)의 정상군 규준(Kang, 2006)에 의거 해 정상 범주에 속하는 자, 2) 신경학적 질환 및 청력 문제가 없 는 자, 3) 최소 1 년 이상의 교육을 받은 자이다.

두 환자군과 정상군 간에 연령, 성별, 교육 연수, $\mathrm{K}-\mathrm{MMSE}$ 의 분포에 대한 동질성 검정 결과 $\mathrm{K}-\mathrm{MMSE}(\mathrm{F}=55.263, p<0.01)$ 를 제외하고 연령 $(\mathrm{F}=1.623, p=0.202)$, 성별 $\left(\chi^{2}=1.084, p=\right.$ $0.582)$, 교육 연수( $\mathrm{F}=1.606, p=0.205)$ 의 분포상 유의미한 차 이는 없었다.

세 집단의 인구통계학적 및 신경심리학적 특성은 Table 1에 제시하였다.

\section{연구 도구}

세 집단의 $\mathrm{HOC}$ 및 의사소통 능력을 알아보기 위해 $\mathrm{BCCD}$ 의 하위 검사를 활용하였다. $\mathrm{BCCD}$ 는 인지 15 개, 의사소통 12 개 등 총 27개 문항을 통해 인지 및 의사소통 능력을 평가하는 도구이 다. 인지의 4 개 하위 검사에는 주의력(선택주의력/분리주의력), 시공간력(시공간 구성), 기억력(구어 및 비구어 작업기억/회상과 재인), $\mathrm{HOC}$ (조직화 능력/추론력/문제 해결력/집행기능) 영역이 포함된다. 의사소통의 4 개 하위 영역은 이해(비유언어/상징 및 기호), 표현(단어유창성/단어 정의/비유언어), 읽기 및 쓰기(읽기 이해/받아쓰기), 화용언어(담화/화용 표현)로 구성된다. 화용언 어의 담화 문항을 제외한 나머지는 모두 문항당 0 2점으로 채 점하며, 담화 문항은 명시된 기준에 따라 최대 8점을 부여한다.

본 연구에서는 조직화 능력, 추론력, 문제 해결력, 집행기능 으로 구성된 $\mathrm{HOC}$ 의 9개 문항, 그리고 이해, 표현, 읽기 및 쓰 기, 화용언어가 포함된 의사소통의 12 개 문항을 활용하였다.

$\mathrm{BCCD}$ 중 본 연구에 활용된 두 영역의 주요 구성은 Table 2 에 제시하였다.

\section{연구 절차}

인구통계학적 및 신경학적 정보, 기타 능력(청력, 시력 등)에 대한 사례 면담을 실시하였고, 정상군의 선별 및 전반적인 인지 수준을 알아보기 위해 K-MMSE를 시행하였다. 이에 따라 선 별된 대상군에게 $\mathrm{BCCD}$ 를 적용해 집단별로 수행력을 알아보

Table 1. Demographic and neuropsychological characteristics of subjects

\begin{tabular}{lcccc}
\hline \multicolumn{1}{c}{ Characteristic } & Control $(\mathrm{n}=40)$ & MCI $(\mathrm{n}=31)$ & DAT $(\mathrm{n}=40)$ & F or $\chi^{2}$ \\
\hline Age $(\mathrm{yr})$ & $73.95( \pm 5.47)$ & $73.87( \pm 5.14)$ & $75.90( \pm 5.98)$ & 1.623 \\
Sex $(\mathrm{M}: \mathrm{F})$ & $21: 19$ & $13: 18$ & $8.05( \pm 3.59)$ & 1.084 \\
Education level $(\mathrm{yr})$ & $9.28( \pm 2.64)$ & $8.26( \pm 3.45)$ & $0.5-2$ & 1.606 \\
CDR (range) & - & 0.5 & $18.63( \pm 5.22)$ & - \\
K-MMSE & $26.70( \pm 1.80)$ & $23.55( \pm 1.86)$ & $55.263^{* *}$ \\
\hline
\end{tabular}

${ }^{* *} p<0.01$. MCI: mild cognitive impairment, DAT: dementia of Alzheimer's type, CDR: clinical dementia rating, K-MMSE: Korean minimental state examination 
았다. 검사는 소음이 최소화된 조용한 방에서 일대일 직접 평 가 방식으로 진행되었고, 수행력은 문항의 특성에 따라 검사자 가 기록지에 기록하거나 피검자가 반응지에 직접 표기하였다. 검사에는 사례 면담 및 $\mathrm{K}-\mathrm{MMSE}$ 가 10 15분, $\mathrm{BCCD}$ 가 20 30 분가량 소요되었다.

본 연구를 위해 세 집단의 $\mathrm{HOC}$ 와 의사소통 능력을 분석하 였다. 담화를 제외한 모든 문항은 명시된 채점 기준에 따라 3점 척도 $(2,1,0)$ 로 점수를 산정하였다. 예를 들어 $\mathrm{HOC}$ 의 문제 해 결력, 의사소통 표현의 단어 정의 등은 채점 기준(예: 핵심 의 미-먹을 때/떠먹을 때/(밥) 풀 때, 밥/국)에 따라 채점하였다. 담 화 문항은 규정된 분석 틀에 따라 응집성 및 통일성은 각각 0 3점, 명제 및 쉼은 0 2점으로 평정하여 최대 8점을 부여하였 다(예: 6개 명제 이상을 회상하여 말한 경우). $\mathrm{HOC}$ 의 총점은 18점, 의사소통은 이해 8점, 표현 8점, 읽기 및 쓰기 4점, 화용 언어 10 점으로 산정되었다. 점수가 높을수록 각 영역의 수행력 이 양호함을 의미한다.

Table 2. Construction of $\mathrm{HOC}$ and communication in Brief test of Cognitive-Communication Disorders

\begin{tabular}{lll}
\hline \multicolumn{1}{c}{ Domain } & \multicolumn{1}{c}{ Subdomain } & $\begin{array}{c}\text { Number } \\
\text { of item }\end{array}$ \\
\hline $\begin{array}{ll}\text { Cognition } \\
\text { HOC }\end{array}$ & Organization & \\
& Reasoning & 2 \\
& Problem solving & 2 \\
Communication & Executive function & 3 \\
Comprehension & Figurative language & 2 \\
& Symbol \& sign & 3 \\
Expression & Word fluency & 1 \\
& Word definition & 2 \\
& Figurative language & 1 \\
Reading/writing & Reading comprehension & 1 \\
& Dictation & 1 \\
Pragmatic language & Discourse & 1 \\
& Pragmatic expression & 1 \\
\hline
\end{tabular}

HOC: higher order cognition

\section{통계 분석}

본 연구에서는 통계 분석 프로그램으로서 SPSS 21.0 version (IBM Corp., Armonk, NY, USA)을 활용하였다. 연령과 성별, 교육 연수, $\mathrm{K}-\mathrm{MMSE}$ 점수상 집단 간의 분포에 차이가 있는지를 확인하기 위해 일원배치 분산분석(one-way analysis of variance)과 카이제곱 검정(chi-squared test)을 사용하였다. 기술통계 및 일원배치 분산분석, Tukey 사후검정을 통해 세 집 단의 $\mathrm{HOC}$ 및 의사소통 능력을 비교하였다. $\mathrm{HOC}$ 와 의사소통 능력 간의 상관성은 피어슨 상관계수(Pearson correlation $\mathrm{CO}^{-}$ efficient) 분석으로 검토하였고, $\mathrm{HOC}$ 를 예측하는 의사소통 영 역은 단계적 다중선형 회귀분석(stepwise multiple linear regression analysis)을 통해 알아보았다.

\section{RESULTS}

\section{$\mathrm{HOC}$ 및 의사소통 수행력의 비교}

두 환자군과 통제군에서 $\mathrm{HOC}$ 와 의사소통 능력에 차이가 있 는지를 비교한 결과는 Table 3과 Figure 1에 제시하였다.

$\mathrm{HOC}$ 는 통제군, $\mathrm{MCI}, \mathrm{DAT}$ 순으로 수행력이 높았고, 세 집 단 간의 차이가 유의미하였다 $(\mathrm{F}=5.537, p<0.01)$. 사후검정 결과, 통제군과 $\mathrm{MCI}$ 집단 간을 제외한 나머지 두 집단 간에 유 의한 차이가 있었다 $(p<0.05)$.

의사소통은 읽기 및 쓰기를 제외하고 모든 하위 영역과 총점 에서 정상 통제군이 가장 높고 DAT 집단이 가장 낮은 수행력 을 보였다. 세 집단 간의 차이는 표현(F=14.708, $p<0.01)$, 화 용언어 $(\mathrm{F}=12.393, p<0.01)$, 총점 $(\mathrm{F}=10.700, p<0.01)$ 에서 유의하였으며, 이해, 읽기 및 쓰기는 유의미한 차이가 없었다. 사후검정 결과 표현, 화용언어, 총점에서 통제군과 $\mathrm{DAT}, \mathrm{MCI}$ 와 DAT 간의 차이가 유의하게 나타났다 $(p<0.01)$.

\section{$\mathrm{HOC}$ 와 의사소통 간의 상관성}

두 환자군과 통제군의 $\mathrm{HOC}$ 와 의사소통 능력 간의 상관성을 알아보았다(Table 4).

$\mathrm{MCI}$ 집단은 이해 $(\mathrm{r}=0.920, p<0.01)$ 와 총점 $(\mathrm{r}=0.618, p<$

Table 3. Performances of $\mathrm{HOC}$ and communication in three groups

\begin{tabular}{lcccc}
\hline \multicolumn{1}{c}{ Characteristic } & Control & MCI & DAT & F \\
\hline HOC & $13.58( \pm 2.78)$ & $13.30( \pm 2.46)$ & & $5.537^{* *}$ \\
Communication & & & & \\
$\quad$ Comprehension & $6.95( \pm 1.58)$ & $6.13( \pm 1.82)$ & $2.13( \pm 2.09)$ & $2.546( \pm 1.63)$ \\
Expression & $4.73( \pm 1.71)$ & $3.77( \pm 0.50)$ & $3.40( \pm 1.06)$ & $14.708^{* *}$ \\
Reading/writing & $3.53( \pm 0.51)$ & $4.54( \pm 1.05)$ & $3.25( \pm 1.11)$ & 2.198 \\
Pragmatic language & $4.62( \pm 1.73)$ & $18.93( \pm 2.15)$ & $15.73( \pm 5.01)$ & $12.393^{* *}$ \\
Total score & $19.82( \pm 4.29)$ & $10.700^{* *}$ \\
\hline
\end{tabular}

${ }^{* *} p<0.01$. HOC: higher order cognition, MCI: mild cognitive impairment, DAT: dementia of Alzheimer's type 
0.01)에서 $\mathrm{HOC}$ 와의 상관을 보였다. DAT 집단의 경우 이해 $(\mathrm{r}=$ $0.810, p<0.01)$, 표현 $(\mathrm{r}=0.738, p<0.01)$, 읽기 및 쓰기 $(\mathrm{r}=$ $0.686, p<0.01)$, 화용언어( $\mathrm{r}=0.595, p<0.01)$ 등 의사소통의 4 개 하위 영역과 총점 $(\mathrm{r}=0.855, p<0.01)$ 에서 모두 HOC와 상관성이 있었다. 통제 집단은 $\mathrm{HOC}$ 와 표현 $(\mathrm{r}=0.440, p<$ $0.01)$, 읽기 및 쓰기 $(\mathrm{r}=0.344, p<0.05)$, 화용언어 $(\mathrm{r}=0.504$, $p<0.01)$, 총점 $(\mathrm{r}=0.532, p<0.01)$ 간에 정적 상관을 보였다.

\section{$\mathrm{HOC}$ 의 예측변인}

두 환자군 및 통제군의 $\mathrm{HOC}$ 를 예측하는 의사소통 영역이 무엇인지를 분석한 결과는 Table 5 에 제시하였다.

$\mathrm{MCI}$ 집단의 $\mathrm{HOC}$ 는 의사소통 영역 중 표현( $\beta=0.540, p<$ $0.01)$, 화용언어 $(\beta=0.651, p<0.01)$, 총점 $(\beta=1.118, p<0.01)$ 을 통해 가장 잘 예측할 수 있었다. DAT 집단에서 $\mathrm{HOC}$ 의 주 요 예측변인은 의사소통 총점으로 나타났다 $(\beta=0.855, p<$ 0.01 ). 통제 집단은 화용언어를 통해 $\mathrm{HOC}$ 를 가장 잘 예측하는 것으로 분석되었다 $(\beta=0.504, p<0.01)$.

\section{DISCUSSIONS}

본 연구에서는 현재 개발 중인 인지-의사소통장애 평가 도

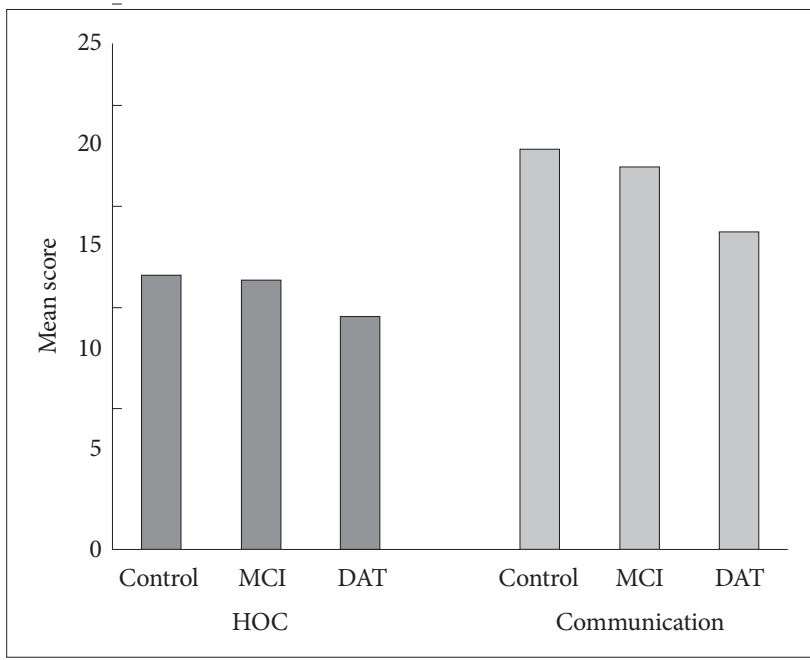

Figure 1. Comparison of performances in three groups. HOC: higher order cognition, $\mathrm{MCl}$ : mild cognitive impairment, DAT: dementia of Alzheimer's type.
구인 $\mathrm{BCCD}$ 의 하위 검사를 활용하여 $\mathrm{MCI}$ 와 $\mathrm{DAT}$ 환자의 $\mathrm{HOC}$ 와 의사소통 간의 상관성을 분석하였다. 이를 통해 $\mathrm{HOC}$ 를 민감하게 반영하는 $\mathrm{BCCD}$ 의 의사소통 영역이 무엇인지를 규명하였다.

\section{$\mathrm{HOC}$ 및 의사소통 수행력의 비교}

본 연구에서 $\mathrm{HOC}$ 및 주요 의사소통 영역은 통제군, $\mathrm{MCI}$, DAT 순으로 수행력이 높았다. 의사소통의 하위 영역 중에는 표현, 화용언어, 총점이 세 집단 간에 유의한 차이를 보였고, 특 히 통제군과 DAT, MCI와 DAT 간의 차이가 유의미하였다. 신 경병리학적 질환이 기억력에 미치는 영향과 비교할 때 $\mathrm{HOC}$ 와 의사소통의 손상은 그 정도와 양상에 차이가 있으나, DAT로 진단되기 이전부터 이들의 변화가 감지된다는 보고가 많다 (Borella et al., 2008; Singh-Manoux et al., 2012). 특히 의사 소통 측면에서는 의미 및 화용 언어 체계가 구문 및 음운 체계 보다 더 손상된다.

$\mathrm{MCI}$ 와 DAT의 언어적 양상 중에는 어휘-의미적 손상이 가 장 두드러진다(Kempler \& Goral, 2008). 이름대기장애(ano$\mathrm{mia}$ )는 주로 의미 및 개념 체계의 손상, 과제에 대한 주의력의 저하, 목표어에 대한 망각, 연관된 경쟁적 반응으로 인한 주의 산란 등에 기인한다. 특히 $\mathrm{MCI}$ 의 자발화는 의미적 기술, 고차 원적 어휘의 감소와 같은 문제를 보인다(Garrard et al., 2005). 이와 유사하게 Venneri et al.(2011)은 DAT로 진단받기 10년 전부터 자발화에 미묘한 변화가 있다고 보고했다. 실제로 $\mathrm{MCI}$ 의 자발화는 초경도 DAT와 매우 흡사하다(Taler \& Phillips, 2008).

본 연구에 활용된 $\mathrm{BCCD}$ 의 표현 영역은 단어유창성, 단어

Table 5. Predictors of higher order cognition in three groups

\begin{tabular}{lll}
\hline \multirow{2}{*}{ Group } & \multicolumn{2}{c}{ Communication } \\
\cline { 2 - 3 } & \multicolumn{1}{c}{ Predictors } & $\beta$-value \\
\hline Control & Pragmatic language & $0.504^{* *}$ \\
MCI & Expression & $0.540^{* *}$ \\
& Pragmatic language & $0.651^{* *}$ \\
& Total score & $1.118^{* *}$ \\
DAT & Total score & $0.855^{* *}$
\end{tabular}

${ }^{* *} p<0.01$. MCI: mild cognitive impairment, DAT: dementia of Alzheimer's type

Table 4. Correlation between $\mathrm{HOC}$ and communication in three groups

\begin{tabular}{llccccc}
\hline \multirow{2}{*}{ Group } & & \multicolumn{5}{c}{ Communication } \\
\cline { 2 - 6 } & & Comprehension & Expression & Reading/writing & Pragmatic language & Total score \\
\hline HOC & Control & 0.306 & $0.440^{* *}$ & $0.344^{*}$ & $0.504^{* *}$ & $0.532^{* *}$ \\
& MCI & $0.920^{* *}$ & 0.064 & 0.023 & 0.243 & $0.618^{* *}$ \\
& DAT & $0.810^{* *}$ & $0.738^{* *}$ & $0.686^{* *}$ & $0.595^{* *}$ & $0.855^{* *}$ \\
\hline
\end{tabular}

${ }^{*} p<0.05,{ }^{* *} p<0.01$. HOC: higher order cognition, MCI: mild cognitive impairment, DAT: dementia of Alzheimer's type 
정의하기, 비유언어로 구성되어 있어 MCI와 DAT의 어휘-의미 적 손상으로 인한 영향과 필연적으로 연계된다. 예를 들어 의미 적 단어유창성은 $\mathrm{MCI}$ 보다 $\mathrm{DAT}$ 에 보다 민감하다(Horton \& Reynolds, 2007). 그러나 기억상실형 MCI (amnestic MCI, $\mathrm{aMCI}$ ) 등 $\mathrm{MCI}$ 의 하위 유형이나 과제에 사용된 의미적 범주에 따라 $\mathrm{MCI}$ 의 수행력이 다르게 나타난다는 보고도 있다(Murphy et al., 2006). 이로 인해 $\mathrm{MCI}$ 와 정상군을 변별하고 민감도 와 특이도가 높은 언어 영역으로 단어유창성을 꼽기도 한다 (Taler \& Phillips, 2008). 단어 정의하기는 통제군, 초경도 및 경 도, 중등도 DAT로 갈수록 질적인 차이를 보이는 과제이다. 또한 모든 DAT 환자는 단어를 정의할 때 핵심 개념을 간과하고 부정 확한 정보를 전달하는 경향이 있다(Lee \& Kim, 2019a).

$\mathrm{MCI}$ 와 DAT는 어휘-의미 측면뿐 아니라 언어를 지원하는 의미기억과 다른 인지 처리도 저하되기 때문에 이를 복합적으 로 반영하는 화용언어 영역이 손상된다. 즉 사회적 상황에서 언 어를 적절히 사용하는 데 어려움이 있다. 특히 전반적인 인지 선 별검사는 $\mathrm{MCI}$ 의 미묘한 화용 문제를 감지하지 못하므로 담화 와 어휘 학습 능력이 유용한 변별적 기능을 한다(Kim \& Lee, 2019a). DAT의 화용언어는 MCI보다 악화되는데, 연관된 정보 를 전달하고 일관적인 담화를 구성하는 데 훨씬 더 어려움을 겪 는다. 또한 주제 변화가 반복적이고 참조물이 불분명할 뿐 아니 라 통일성과 정보성이 부족하다(Kim \& Lee, 2019b; McDermott \& Chan, 2006).

본 연구에 적용된 화용언어 영역은 담화 및 화용 표현으로 구성되어 $\mathrm{MCI}$ 와 DAT 집단 간을 변별하는 데 일조하였다. 특 히 담화 과제가 복잡성에 따라 정상군과 $\mathrm{MCI}$ 또는 정상군과 초기 DAT 간의 차이를 민감하게 반영한다는 선행연구 결과와 도 일치한다(Taler \& Phillips, 2008), 예를 들어 aMCI와 DAT 의 담화를 비교한 연구(Kim \& Lee, 2019b)에서 $\mathrm{aMCI}$ 는 정상 군에 비해 새로운 명제를 더 적게 산출하는 반면, 심 길이는 $\mathrm{aMCI}$ 및 $\mathrm{DAT}$ 집단이 더 길었다. 또한 DAT의 응집성 및 담화 총점은 $\mathrm{aMCl}$ 에 비해 유의하게 낮았다.

한편, 본 연구에서 의사소통 영역의 이해, 읽기 및 쓰기는 세 집단 간에 유의미한 차이가 없었다. 특히 이해 측면은 $\mathrm{MCI}$ 와 DAT 집단을 변별하지 못했는데, 이는 언어의 해석과 처리가 $\mathrm{HOC}$, 작업기억, 주의력 등 다영역적 인지에 보다 민감한 데 기 인한다(Peach \& Shapiro, 2020). 본 연구의 DAT 집단에 경도 수준의 대상군이 다수 포함된 점도 영향을 미친 것으로 보인 다. 또 본 연구에서 활용한 읽기 및 쓰기 문항의 수가 상대적으 로 적고 난이도가 낮은 점 등이 집단 간의 수행력 차이를 희석 시킨 것으로 판단된다.

\section{$\mathrm{HOC}$ 와 의사소통 간의 상관성}

본 연구에서 나타난 수행력의 차이를 기반으로 $\mathrm{HOC}$ 와 의사 소통 간의 상관성을 분석한 결과 $\mathrm{MCI}$ 집단은 이해와 총점, $\mathrm{DAT}$ 집단은 의사소통의 모든 하위 영역과 총점에서 $\mathrm{HOC}$ 와 정적 상관을 보였다. 이는 DAT의 초기부터 행동이나 일의 계 획과 조직, 개시와 관련된 집행기능이 손상되는 것과 연관된다 (Taler \& Phillips, 2008). 또한 MCI와 임상 전 단계의 DAT도 $\mathrm{HOC}$ 와 일화기억, 주의력, 언어 능력이 함께 저하된다. 따라서 $\mathrm{MCI}$ 와 DAT는 공통적으로 의미를 탐색하는 과정에서 $\mathrm{HOC}$ 기능이 제대로 발휘되지 못한다. 이러한 상관성 때문에 어휘의미적 결함이 신경병리학적 질환의 초기부터 뚜렷이 나타난 다. DAT의 자발화에서는 이 같은 경향이 더욱 심화되는데, 단 순하고 자동화된 문장, 목표어를 대체하는 상위 범주의 어휘, 에두르기, 목표어와 무관한 어휘 등이 빈번하다. 즉 의미적 탐 색이나 운영 과정에서 $\mathrm{HOC}$ 가 미치는 부정적인 영향이 매우 크다(Duong et al., 2006).

$\mathrm{MCI}$ 의 언어 이해는 과제별로 다르게 나타날 수 있다. $\mathrm{MCI}$ 는 의미적 네트워크가 손상되기 때문에 어휘 판단 과제에서 모호 한 명사를 잘 처리하지 못한다(Taler \& Jarema, 2006). MCI가 의미 연상 과제를 수행하지 못한다는 사실을 상측두고랑 $\left(\mathrm{su}^{-}\right.$ perior temporal sulcus)의 비활성화를 통해 규명한 연구도 있 다(Vandenbulcke et al., 2007). 의미를 처리하는 데 있어 의도 적 및 자동적 측면 간에 차이도 존재한다. 예를 들어 이름 대기 와 단어유창성은 의도적인 처리를 요하나 어휘 판단 및 확인은 보다 자동적인 처리를 요한다. $\mathrm{MCI}$ 의 경우 의도적 처리는 손상 되나 자동적 처리가 유지되며, DAT는 두 영역에서 모두 결함 이 있다(Duong et al., 2006). 그러나 MCI도 DAT와 유사한 양 상을 보인다는 보고도 있다(Taler \& Jarema, 2006). 즉, 의미를 탐색하는 동안 억제와 같은 $\mathrm{HOC}$ 능력이 크게 관여하므로 의 도적 처리뿐 아니라 자동적 처리까지 모두 손상된다는 것이다. $\mathrm{MCI}$ 집단에서 이해와 $\mathrm{HOC}$ 간의 상관성이 유의미하게 나타난 본 연구 결과 역시 이와 동일한 맥락이라고 볼 수 있다.

$\mathrm{MCI}$ 와 달리 $\mathrm{DAT}$ 는 문장의 이해에서 결함이 있으나 변이적 이며, 초경도 단계부터 오류를 보이는 경향이 있다. 예컨대 담화 이해에서 DAT는 요약, 주요 주제, 교훈 등 핵심적 수준(gist-level)을 처리하는 데 어려움이 크다(Hudon et al., 2006). 특히 MCI 에 비해 DAT는 핵심적 수준의 담화에 대한 재인 과제를 거의 수행하지 못한다. 의사소통의 모든 영역이 $\mathrm{HOC}$ 와 유의미한 상 관성을 보인 본 연구 결과는 신경병리학적 질환이 심화될수록 $\mathrm{HOC}$ 의 영향력이 확대됨으로써 이해, 표현, 화용언어 등 의사 소통 영역 전반에 보다 광범위하게 관여함을 의미한다. 


\section{$\mathrm{HOC}$ 의 예측변인}

마지막으로, 본 연구에서는 $\mathrm{BCCD}$ 의 의사소통 영역 중 $\mathrm{HOC}$ 를 민감하게 반영하는 예측변인을 알아보았다. 그 결과 $\mathrm{MCI}$ 집 단은 표현, 화용언어, 총점, 그리고 DAT 집단은 의사소통 총점 이 $\mathrm{HOC}$ 의 주요 예측변인으로 분석되었다. DAT는 임상적으로 진단되기 10 15년 전부터 질환이 시작된다고 알려져 있다 (Bateman et al., 2012). 따라서 조기 진단의 시행 및 정확도, 예 방적 조치가 매우 중요하다. 이 같은 맥락에서 $\mathrm{MCI}$ 는 더욱 큰 임상적 함의를 갖는다. 즉 DAT의 임상 전 단계 또는 전조 증상 으로서 $\mathrm{MCI}$ 를 주목할 필요가 있다. 실제로 $\mathrm{MCI}$ 는 동일 연령 의 정상군에 비해 DAT로의 진행률이 10 배 이상 높다고 보고 된다(Bateman et al., 2012).

지금까지는 MCI에서 DAT로의 진행을 예측하는 변인으로서 주로 기억력에 중점을 두었다. MCI와 DAT의 초기부터 일화기 억, 지연기억 등 기억력의 손상이 가장 두드러지기 때문이다. 그 러나 예측적 정확도를 보다 높이기 위해서는 기억력 이외의 인 지-언어 영역에 대한 고려가 필요하다(Belleville et al., 2017). 여기에는 주로 $\mathrm{HOC}$ 와 언어, 작업기억 등이 포함된다(Östberg et al., 2005). 즉, DAT의 예측변인으로서 다영역적이고 복합적 인 측면이 필수적으로 강조되는 추세이다.

$\mathrm{HOC}$ 는 $\mathrm{MCI}$ 에서 $\mathrm{DAT}$ 로의 진행을 예측하는 주요 지표로서 유용하다(Belleville et al., 2017). 치매가 진행되면서 HOC와 의사소통 능력의 손상이 더욱 뚜렷해지기 때문이다(Kumar et al., 2015). 이러한 맥락에서 볼 때 HOC와 의사소통 능력 간의 상관성은 예측적 정확도를 높이고 다른 생물표지(biomarker) 에 비해 질적 가치를 제공한다는 점에서 의미가 있다. 예를 들 어 $\mathrm{MCI}$ 는 정상군에 비해 고도의 인지적 부담을 요하는 $\mathrm{HOC}$ 관련 활동이 저하되므로, 이와 상관성을 갖는 인지-언어 영역으 로서 상호 예측이 가능하다(Reppermund et al., 2013). 실제로 적응 및 기제의 처리, $\mathrm{HOC}$ 가 저하된 $\mathrm{aMCI}$ 는 단기간에 $\mathrm{DAT}$ 로 전환될 확률이 가장 높다(Reppermund et al., 2013). 이에 가장 직결되는 영역으로 기억력과 함께 언어 능력이 꼽힌다. 언어는 인지적 자원을 다양하게 요구하는 복잡한 활동이므로 신경병 리학적 진단에 매우 중요하다. $\mathrm{MCI}$ 의 $\mathrm{HOC}$ 가 표현 및 화용언 어를 통해 가장 잘 예측된다는 본 연구 결과는 $\mathrm{MCI}$ 의 이 같은 특수성을 뒷받침한다. 또 다른 연구에서도 자기 모니터링, 세트 전환, 작업기억 등 집행기능 관련 요소와 함께 단어유창성, 대 면이름대기 등의 언어 능력이 $\mathrm{MCI}$ 의 강력한 예측인자로 제시 된 바 있다(Östberg et al., 2005).

$\mathrm{HOC}$ 의 예측변인을 고려할 때 DAT의 초기 단계에 주목할 필요가 있다. 즉 DAT는 초기부터 어휘-의미적 손상이 뚜렷하 고 언어 처리의 효율성이 떨어진다. 화용 체계의 변화로 비유언 어의 해석과 표현, 담화의 산출에 매우 큰 어려움이 있다(Kim
\& Lee, 2019b; Ostberg et al., 2005). 이에 대한 가장 강력한 영 향 요인은 집행기능을 포함한 $\mathrm{HOC}$ 의 손상이다. 즉 $\mathrm{HOC}$ 는 질 환의 초기부터 저하되기 시작해 중증도에 따라 손상이 더욱 심 화되기 때문이다. 예를 들어 DAT의 중기에는 계획화 능력이 크게 떨어지므로 이를 요하는 다양한 인지-언어 과제에서 모 순된 전략과 오류가 현저히 나타난다(Rainville et al., 2002). 따라서 DAT의 전반적인 의사소통 능력은 $\mathrm{HOC}$ 를 민감하게 반 영할 수 있다(Hough, 2007; Lee \& Kim, 2019a). DAT의 HOC 가 의사소통 총점을 통해 가장 잘 예측된다는 본 연구 결과도 이와 일맥상통한다.

요컨대 본 연구는 MCI와 DAT의 HOC 및 의사소통 능력을 비교하고 그 상관성을 분석함으로써 두 신경병리학적 질환군 의 진단과 중재에 활용할 수 있는 규준 자료를 제시하였다. 또 한 현재 개발 중인 인지-의사소통장애 평가도구인 $\mathrm{BCCD}$ 에서 $\mathrm{HOC}$ 를 민감하게 반영하는 의사소통의 하위 영역이 무엇인지 를 검증함으로써 임상적으로 유용한 예측적 지표를 마련하였 다. 이들을 임상적 및 신경생물학적 지표와 결합하여 $\mathrm{MCI}$ 및 DAT에 대한 최적의 예측적 알고리즘을 도출함으로써 진단적 정확도와 중재 효과를 높이는 데 크게 기여할 수 있을 것이다.

본 연구의 제한점 및 향후 연구를 위한 제언은 다음과 같다. 첫째, 연령과 교육 연수는 $\mathrm{HOC}$ 와 의사소통에 영향을 주는 주 요 변인 중 하나이다(Lee \& Kim, 2019b). 추후에는 두 환자군 의 연령과 교육 연수를 세분화한 연구가 필요할 것이다. 둘째, 대상군별로 민감한 지표를 확인하는 연구이므로 정상군의 선 정기준을 보다 엄격화할 필요가 있을 것이다. 예컨대 청력 손상 여부에 대해 직접적으로 선별검사를 시행하고 교육 연수도 보 다 다양화할 수 있다. 셋째, $\mathrm{HOC}$ 와 의사소통의 수행력에 관여 하는 다른 인지 요인을 고려해야 한다(Belleville et al., 2017). 즉, 작업기억, 주의력, 시지각력, 정보 처리 속도 등의 변수를 추 가해 상관관계를 살펴볼 필요가 있다. 넷째, 다른 신경학적 질 환군과의 비교를 통해 MCI와 DAT의 변별적 양상을 제시할 수 있을 것이다. 예를 들어 실어증, 외상성 뇌 손상, 우반구 손상, $\mathrm{aMCI}$ 등 MCI의 하위 유형, 혈관성 치매(vascular dementia) 등 다양한 치매 유형의 $\mathrm{HOC}$ 및 의사소통과 비교할 수 있다.

중심 단어 : 의사소통·상관성·알츠하이머형 치매·고차원적 인지·경도인지장애.

\section{Ethical Statement}

We explained exactly the purpose and process of this study to all participants in advance. And they agreed to participate in it. This study was approved by the Institutional Review Board (\#HUGSAUD461850, \#201908-010-002).

\section{Acknowledgments}

The authors thank to the participants. 


\section{Declaration of Conflicting Interests}

There are no conflict of interests.

\section{Funding}

This work was supported by the Korean Association of Speech-Language Pathologist in 2019 (research fund for empowerment of speech therapy).

\section{Author Contributions}

All authors contributed equally to this work. M.L. designed and performed experiments, analyzed data, and wrote the paper; M.L. and B.K. designed and performed experiments in the clinic; M.L. provided statistical analysis and critical revision. Also, the authors discussed the results together and implications and commented on the manuscript at each stage.

\section{ORCID iDs}

Mi Sook Lee

https://orcid.org/0000-0001-9255-565X

Bo Seon Kim

\section{REFERENCES}

American Association for the Advancement of Science (2009). Final Report of a National Conference: Vision And Change in Undergraduate Biology Education: A Call to Action. Washington, DC: Association of American Medical Colleges.

Bateman, R. J., Xiong, C., Benzinger, T. L. S., Fagan, A. M., Goate, A., Fox, N. C., et al. (2012). Clinical and biomarker changes in dominantly inherited Alzheimer's disease. The New England Journal of Medicine, 367(9), 795-804.

Belleville, S., Fouquet, C., Hudon, C., Zomahoun, H. T. V., \& Croteau, J.; Consortium for the Early Identification of Alzheimer's disease-Quebec. (2017). Neuropsychological measures that predict progression from mild cognitive impairment to Alzheimer's type dementia in older adults: A systematic review and meta-analysis. Neuropsychology Review, 27(4), 328-353.

Billington, J., Carroll, J., Davis, P., Healey, C., \& Kinderman, P. (2013). A literature-based intervention for older people living with dementia. Perspectives in Public Health, 133(3), 165-173.

Borella, E., Carretti, B., \& De Beni, R. (2008). Working memory and inhibition across the adult life-span. Acta Psychologica, 128(1), 33-44.

Duong, A., Whitehead, V., Hanratty, K., \& Chertkow, H. (2006). The nature of lexico-semantic processing deficits in mild cognitive impairment. Neuropsychologia, 44(10), 1928-1935.

Garrard, P., Maloney, L. M., Hodges, J. R., \& Patterson, K. (2005). The effects of very early Alzheimer's disease on the characteristics of writing by a renowned author. Brain, 128(Pt 2), 250-260.

Hillis, A. E., Chang, S., Breese, E., \& Heidler, J. (2004). The crucial role of posterior frontal regions in modality specific components of the spelling process. Neurocase, 10(2), 175-187.

Hitch, G. J., Towse, J. N., \& Hutton, U. (2001). What limits children's working memory span? Theoretical accounts and applications for scholastic development. Journal of Experimental Psychology: General, 130(2), 184198.

Horton, A. M. Jr. \& Reynolds, C. R. (2007). Early detection of risk of onset for dementia of the Alzheimer type and subtle executive dysfunction after TBI using the test of verbal conceptualization and fluency during clinical neuropsychological assessment: Two case studies. Applied Neuropsychology, 14(3), 224-229.

Hough, M. S. (2007). Incidence of word finding deficits in normal aging. Folia Phoniatrica et Logopaedica, 59(1), 10-19.

Hudon, C., Belleville, S., Souchay, C., Gely-Nargeot, M. C., Chertkow, H., \& Gauthier, S. (2006). Memory for gist and detail information in Alzheimer's disease and mild cognitive impairment. Neuropsychology,

20(5), 566-577.

Kang, Y. W. (2006). A normative study of the Korean-mini mental state examination (K-MMSE) in the elderly. Korean Journal of Psychology, 25(2), 1-12.

Kemper, S. \& Summer, A. (2001). The structure of verbal abilities in young and older adults. Psychology and Aging, 16(2), 312-322.

Kemper, S., Thompson, M., \& Marquis, J. (2001). Longitudinal change in language production: Effects of aging and dementia on grammatical complexity and propositional content. Psychology and Aging, 16(4), 600614.

Kempler, D. \& Goral, M. (2008). Language and dementia: Neuropsychological aspects. Annual Review of Applied Linguistics, 28, 73-90.

Kim, B. S. \& Lee, M. S. (2019a). Effects of reading and writing intervention on word retrieval of people with dementia. Journal of Special Education and Rehabilitation Science, 58(2), 217-236.

Kim, B. S. \& Lee, M. S. (2019b). Scoring method according to severity of impaired discourse production in normal elderly, amnestic mild cognitive impairment, and dementia. Journal of Special Education and Rehabilitation Science, 58(1), 347-365.

Kumar, R., Koirala, P., \& Tiwari, S. C. (2015). Higher mental functioning in dementia: A status assessment. Journal of Geriatric Mental Health, 2(1), 42-45.

Lee, M. S. \& Kim, B. S. (2018). Correlation between figurative language and cognitive-linguistic ability in older adults by age. Journal of Special Education and Rehabilitation Science, 57(4), 115-137.

Lee, M. S. \& Kim, B. S. (2019a). Characteristics of word fluency in healthy aging and Alzheimer's disease. Audiology and Speech Research, 15(2), 135-143.

Lee, M. S. \& Kim, B. S. (2019b). A preliminary study for the development of brief test of cognitive-communication disorders (BCCD). Journal of Special Education and Rehabilitation Science, 58(4), 321-344.

Lee, M. S. \& Kim, B. S. (2020). Transfer effects of working memory intervention on linguistic abilities in patients with dementia. Audiology and Speech Research, 16(1), 58-69.

Lemons, P. P. \& Lemons, J. D. (2013). Questions for assessing higher-order cognitive skills: It's not just Bloom's. CBE Life Sciences Education, 12(1), 47-58.

Longden, E., Davis, P., Carroll, J., Billington, J., \& Kinderman, P. (2016). An evaluation of shared reading groups for adults living with dementia: Preliminary findings. Journal of Public Mental Health, 15(2), 75-82.

McDermott, K. B. \& Chan, J. C. K. (2006). Effects of repetition on memory for pragmatic inferences. Memory and Cognition, 34(6), 1273-1284.

McDowd, J., Hoffman, L., Rozek, E., Lyons, K. E., Pahwa, R., Burns, J., et al. (2011). Understanding verbal fluency in healthy aging, Alzheimer's disease, and Parkinson's disease. Neuropsychology, 25(2), 210-225.

Morris, J. C. (1993). The clinical dementia rating (CDR): Current version and scoring rules. Neurology, 43(11), 2412-2414.

Murphy, K. J., Rich, J. B., \& Troyer, A. K. (2006). Verbal fluency patterns in amnestic mild cognitive impairment are characteristic of Alzheimer's type dementia. Journal of the International Neuropsychological Society, 12(4), 570-574

Östberg, P., Fernaeus, S. E., Hellström, Å., Bogdanović, N., \& Wahlund, L. O. (2005). Impaired verb fluency: A sign of mild cognitive impairment. Brain and Language, 95(2), 273-279.

Peach, R. K. \& Shapiro, L. P. (Trans. Lee, M. S. \& Kim, S. R.) (2020). Cognition and Acquired Language Disorders: An Information Processing Approach. (1st ed.). Seoul: Hakjisa.

Pushkar, D., Basevitz, P., Arbuckle, T., Nohara-LeClair, M., Lapidus, S., \& Peled, M. (2000). Social behavior and off-target verbosity in elderly people. Psychology and Aging, 15(2), 361-374.

Rainville, C., Amieva, H., Lafont, S., Dartigues, J. F., Orgogozo, J. M., \& Fabrigoule, C. (2002). Executive function deficits in patients with dementia of the Alzheimer type: A study with a Tower of London task. Archives of Clinical Neuropsychology, 17(6), 513-530.

Reppermund, S., Brodaty, H., Crawford, J. D., Kochan, N. A., Draper, B., 
Slavin, M. J., et al. (2013). Impairment in instrumental activities of daily living with high cognitive demand is an early marker of mild cognitive impairment: The Sydney Memory and Ageing Study. Psychological Medicine, 43(11), 2437-2445.

Singh-Manoux, A., Kivimaki, M., Glymour, M. M., Elbaz, A., Berr, C., Ebmeier, K. P., et al. (2012). Timing of onset of cognitive decline: Results from Whitehall II prospective cohort study. The BMJ: British Medical Journal, 344, d7622.

Sperling, R. A., Aisen, P. S., Beckett, L. A., Bennett, D. A., Craft, S., Fagan, A. M., et al. (2011). Toward defining the preclinical stages of Alzheimer's disease: Recommendations from the National Institute on AgingAlzheimer's Association workgroups on diagnostic guidelines for Alzheimer's disease. Alzheimer's and Dementia, 7(3), 280-292.
Taler, V. \& Jarema, G. (2006). On-line lexical processing in AD and MCI: An early measure of cognitive impairment? Journal of Neurolinguistics, 19(1), 38-55.

Taler, V. \& Phillips, N. A. (2008). Language performance in Alzheimer's disease and mild cognitive impairment: A comparative review. Journal of Clinical and Experimental Neuropsychology, 30(5), 501-556.

Vandenbulcke, M., Peeters, R., Dupont, P., Van Hecke, P., \& Vandenberghe, R. (2007). Word reading and posterior temporal dysfunction in amnestic mild cognitive impairment. Cerebral Cortex, 17(3), 542-551.

Venneri, A., Gorgoglione, G., Toraci, C., Nocetti, L., Panzetti, P., \& Nichelli, P. (2011). Combining neuropsychological and structural neuroimaging indicators of conversion to Alzheimer's disease in amnestic mild cognitive impairment. Current Alzheimer Research, 8(7), 789-797. 